\title{
Home Production Technology and Time Allocation: Empirics, Theory, and Implications
}

\author{
Lei Fang and Guozhong Zhu
}

\section{Working Paper 2012-19}

December 2012

\begin{abstract}
We document a set of time use patterns in both time series and cross sections. To explain these facts, we propose and estimate a model of time allocation that emphasizes the role of home production technology. We find it necessary to consider both labor-augmenting technology and total factor productivity in home production. Based on the estimated model, we study the effects of proportional tax and lump-sum transfer on time allocation and labor supply, with the roles of home production technology and wage heterogeneity highlighted.
\end{abstract}

JEL classification: J22, J24

Key words: time allocation, home production, technology

The authors thank Russell Cooper, Daniel Hamermesh, and Richard Rogerson for their insightful comments. They also thank seminar participants at the University of Texas, Shanghai Jiaotong University and the 2012 Midwest Macro Meeting. They thank Mark Aguiar and Erik Hurst for their Stata programs, which make time-use data much easier to work with. The views expressed here are the authors' and not necessarily those of the Federal Reserve Bank of Atlanta or the Federal Reserve System. Any remaining errors are the authors' responsibility.

Please address questions regarding content to Lei Fang, Research Department, Federal Reserve Bank of Atlanta, 1000 Peachtree Street, N.E., Atlanta, GA 30309-4470, 404-498-8057, lei.fang@atl.frb.org, and Guozhong Zhu, Department of Applied Economics, Guanghua School of Management, Peking University, 86-10-62767407, gzhu@gsm.pku.edu.cn.

Federal Reserve Bank of Atlanta working papers, including revised versions, are available on the Atlanta Fed's website at frbatlanta.org/pubs/WP/. Use the WebScriber Service at frbatlanta.org to receive e-mail notifications about new papers. 


\section{Introduction}

Time allocation is an important economic activity. It is related to key issues such as labor supply and consumer expenditure. The literature has recognized the importance of home production in the study of time allocation. One of the ingredients of home production is the technology. The improvements of home production technology, partially embodied in the use of clothes dryer, mircowave oven, email, etc., have profoundly changed our time allocation.

We formally study how home production technology shapes time allocation. The point of departure is a set of time use patterns in both time series and cross sections. In the spirit of time use trichotomy formalized by Gronau (1977), we study three time use categories market hours, home hours (home production time) and leisure. We show that in time series, the rise of wage rate is accompanied by rising leisure and declining market hours and home hours. Home production time has declined to larger extent than market hours. Besides the declining trends, market hours and home hours co-move negatively. In cross sections, we show that wage is negatively correlated with leisure and home hours, and positively correlated with market hours. Thus, the correlation between wage rate and leisure (also between wage rate and market hours) in cross sections is the opposite of that in time series.

The above rich time use patterns are not consistent with a standard textbook model where leisure-work decision depends only on the income and substitution effects of wage rate. It is also difficult to explain them with a standard home production model in which home production technology is typically assumed to be labor-augmenting. Therefore, we propose a time allocation model that features two types of home production technology. The first one is labor-augmenting technology, called LAT, that increases the productivity of home hours. The most prominent improvement of LAT is perhaps the adoption of new consumer durables such as micro-wave, dish washer, washer and 
drier, and vacuum cleaner. ${ }^{1}$ The second one is the technology that increases the productivity of both time input and goods input in home production, and it is called TFP of home production. An example of TFP is the improvement of infrastructure - a new high way makes errands running not only less expensive (less gas burning), but also less time consuming. Another example is the popularization of department stores which has improved the efficiency of both time input and goods input (transportation fare) of shopping trips. The emergence of specialized stores, such as Home Depot, has similar effects. ${ }^{2}$

We show that with proper growth rates of home production technology, our model is able to generate the observed time use patterns in both time series and cross sections. Intuitively, the relative labor productivity between market production and home production (LAT relative to wage rate) determines the allocation of work hours between the two sectors. In cross sections, agents adopt similar LAT, thus higher-wage agents work more in the market and less at home, provided that market goods and home time are substitutes in home production. $^{3}$ Over time, production time is shifted from home to the market when wage rate grows more quickly then LAT, and vice versa, hence the negative co-movement between market hours and home hours in the data. In addition, the rise in home production TFP in time series shifts the allocation of time from work (both at home and in the market) to leisure when the substitutability between leisure and consumption is low in the utility function. Thus, although leisure appears to be positively correlated with wage in time series, the rise is not driven by the rise in wage, but driven by the improvements in home production TFP. Without the rise in TFP, higher wage rate

\footnotetext{
${ }^{1}$ Campbell and Ludvigson (2001) model consumer durables explicitly which is taken as part of the exogenous LAT in our model.

${ }^{2}$ Aguiar and Hurst (2007b) show that goods input of shopping, measure by money, can be substituted by time to large extent.

${ }^{3}$ The finding in Costa (2000), that in 1890s higher wage individuals worked less hours, is also understandable if these individuals adopted much better home production technology than the poorer ones, which is possible in a more inequal society.
} 
leads to less leisure as described by the cross sectional correlation.

We estimate the growth rates of both types of home production technology along with the parameters in home production function and utility function. During 1965-2003, LAT increased by about $80 \%$. In the meantime TFP increased by between $31 \%$ to nearly four-fold, depending on the measure of leisure used. ${ }^{4}$ The estimation finds high substitutability between home time and market goods in home production, and low substitutability between leisure and consumption in the utility function.

We use the estimated model to study how proportional income tax and lump-sum transfer affect time allocation and labor supply. We find that the response of time allocation to the policy increases with the levels of home production technology, but decreases with wage rate. One of the implications is that wage distribution matters, and the predicted policy effect from a representative agent model can be quite inaccurate. We find that the representative agent model on average understates the negative policy effect on market labor supply by about $8 \%$.

Our empirical study is based on three different household surveys - the American Time Use Survey (ATUS), the Current Population Survey (CPS) and the Consumer Expenditure Survey(CEX). To link the three data sets, we break households in each survey into income deciles, and calculate averages of wage rate, expenditure and various time use categories for each decile. These decile averages enable us to document time use patterns and estimate model parameters.

This paper complements the literature of home production by highlighting the roles of home production technology. The existing research has been successful in demonstrating how home production sector introduces more volatility to macroeconomic variables long the business cycle (e.g.,Greenwood and Hercowitz (1991), Benhabib et al. (1991), and McGrattan et al. (1997), Campbell and Ludvigson

\footnotetext{
${ }^{4}$ Leisure is very sensitive to TFP. Thus different measure of leisure leads to very different TFP growth.
} 
(2001)). Using home production models to study the effects of income taxation on labor supply has also been very fruitful (e.g.,Rogerson (2008), Rogerson (2009) and McDaniel (2011)). In these studies, home production technology is restricted to be labor-augmenting. In addition, the existing studies pay little attention to the labor productivity at home relative to that in the market. One exception is McDaniel (2011) that assumes home production productivity to grow at a constant rate which is different from market productivity. In contrast, our paper explicitly estimates the growth of two types of home production technology, and examine its impacts on time allocation.

Empirically this paper contributes to the literature by painting a comprehensive picture of time use patterns in both time series and cross sections. A number of existing empirical studies have documented similar time series trends. Aguiar and Hurst (2007a) find that both market hours and home hours have decreased by more than 4 hours per week on average between 1965-2003. In the meantime, leisure exhibited significant increase. Greenwood and Vandenbroucke (2005) show a plunge of average market hours per week from 70 hours to 41 hours during 1831-2002. ${ }^{5}$ In cross sections, there exist studies that are implicitly related to the correlation between wage and time allocation. Kuhn and Lozano (2008) find that highly-educated, high wage men have a tendency to work longer. Juhn and Murhpy (1997) find that wives of middle and high wage men experienced the largest increase in hours worked during 1968-1992. Costa (2000) concludes that between 1973-1991 the most highly paid worked more hours than the lowest paid. Aguiar and Hurst (2007a) document a negative correlation between education attainment and leisure hours in cross sections. Hamermesh and Lee (2007) find that more time stress is perceived by adults in households with higher earnings. However none of these studies explicitly documents how wage rate correlates with market hours, home hours and leisure.

\footnotetext{
${ }^{5}$ For a comprehensive review of historical time use data,see Robert Whaples' article on EH.NET, http://eh.net/encyclopedia/article/whaples.work.hours.us.
} 
Another contribution of this paper is the joint estimation of two critical parameters in home production literature - elasticities of substitution between goods and time in home production, and between consumption and leisure in the preference. The former has been estimated/calibrated using either aggregate data (McGrattan et al. (1997) and Chang and Schorfheide (2003)) or micro data (Rupert et al. (1995) and Aguiar and Hurst (2007b)). We employ a different source of identification (the time use pattern in both time series and cross sections) and reach a similar estimate. For the latter, much of the existing research has assumed a unit elasticity so that balanced growth path exists. Our estimation shows that an elasticity below one is necessary to explain the negative correlation between leisure and wage rate in cross sections.

The rest of the paper is organized as follows. Section II discusses the data and data facts. Section III lays out the model. Section IV discusses estimation strategy and reports the estimation results. Section $\mathrm{V}$ uses the estimated model to study proportional income tax and lump-sum transfer. VI concludes.

\section{Data}

Three different household surveys are used in this paper - the American Time Use Survey (ATUS), the Current Population Survey (CPS) and the Consumer Expenditure Survey (CEX). Details about these surveys are provided in Appendix A. From 1965 to 2003, only five waves of ATUS exist, conducted in 1965, 1975, 1985, 1993 and 2003 respectively. Thus we choose five corresponding waves of CEX and CPS. $^{6}$

${ }^{6}$ There exists no CEX survey in 1965 and 1975, so we interpolate expenditures from 1961 and 1973 surveys. See Appendix A for details. 


\subsection{Construction of Decile Level Data}

To study the correlation between wage rate and time allocation, it is necessary to have information on both for each agent. Detailed micro data on time allocation is available in ATUS. However, Early waves of ATUS have very limited information on wage. On the other hand, CPS provides high quality data on wage for each member in a family. Furthermore, the estimation of our model entails expenditure data which are available from CEX, but not from ATUS or CPS. Therefore we link the three data sources according to household income which is available in each of the three data sets. ${ }^{7}$

Linking Three Surveys To link the three data sets together, we first apply the same sample selection criteria to each survey. We exclude households whose heads were (i)not married (ii) unemployed (iii) younger than 25 (iv) older than 60 . Next, we break the respondents in each wave of survey into 10 groups based on the reported household income. ${ }^{8}$ Finally, for households in each income decile, we calculate the average wage rate in CPS, average expenditure in CEX, and averages of market hours, home hours and leisure in ATUS. Our analysis below is based on these averages. A side benefit of the decile level analysis is that it averages out the high frequency movements in wage, consumption and time use caused by idiosyncratic shocks. Since each of the three surveys has sample sizes that are big enough to be nationally representative, we can assume these averages represent the typical situation for each income decile.

Decision Making Units Following the insights of Mincer (1962), we take household to be the decision-making unit, and focus on mar-

\footnotetext{
${ }^{7}$ To estimate the elasticity of substitution between time and goods in home production, Aguiar and Hurst (2007b) also link two data set - ATUS and ACNielsen's Homescan Panel that provides information on shopping trips and grocery expenditure.

${ }^{8}$ Household income is available in each waves of the three surveys, except in ATUS85. We impute household income for respondents in ATUS85 by estimating income equation in the corresponding CPS.
} 
ried couples. CEX reports expenditures at household level which fits our study well.

CPS records wage rate for each household member. For each income decile we calculate the average wage rate for husband and wife separately. Since some wives did not work, we calculate the average wage rate of working wives only. Then in each decile, we take the average of the two wage rates as the household wage rate. This treatment also prevents the increasing female labor market participation from affecting the decile level wage rate.

Prior to 2003, ATUS provides information on individual respondents only. ${ }^{9}$ Therefore we calculate income decile level time use as the averages of married working respondents, with the demographic weights and day weights applied.

Demographic Weights and Day Weights of ATUS Re-
spondents Time allocation depends critically on sex, age and number of children. These demographics are not included in our model, so they need to be controlled for. ${ }^{10}$ To do so we construct demographic cells based on age, sex and presence of children, and calculate the percentage of respondents that fall into each cell in ATUS65. These percentages, called the fixed demographic weights, are applied to later waves of ATUS.

Days in the week are not uniformly represented in the ATUS sample. For example, of the respondents in ATUS75, 5.88\% were interviewed on Saturdays and 19.39\% interviewed on Sundays. This causes huge bias if the day weight is not taken into account. Following Aguiar and Hurst (2007a), We use the weights to ensure each day of the week is uniformly represented.

\footnotetext{
${ }^{9}$ In 1975 survey, there were survey questions for both respondents and spouses, but the information collected from spouses is much scarcer and less accurate.

${ }^{10}$ The effects of demographics on time allocation can be significant. Rupert et al. (2000) find that over lifecycle home hours and wage are positively correlated.
} 
Other Measurement Issues To break total time into home hours, market hours and leisure, we follow the time use taxonomy in Aguiar and Hurst (2007a), and define the three time use variables consistently through different waves of time use surveys. Specifically, four measures of leisure are defined, with leisure 1 being the narrowest definition and leisure 4 being the broadest. Major activities in each leisure measure are given in Appendix A.

Wage rate and expenditures are in 1965 dollars. We deflate earnings and expenditures using Price Indexes for Personal Consumption expenditures from NIPA table 2.5.4..

We calculate after-tax wage rates based on the reported Federal and state tax liabilities in CPS. In the three earlier waves of CPS, tax liabilities were not reported, so we impute them using internet TAXSIM model provided by NBER.

\subsection{Data Facts}

Table 1 shows the cross sectional correlation coefficients between wage and time use at income decile level. In each cross section, wage rate is negatively correlated with each of the four measures of leisure, and positively correlated with market hours. Wage rate is negatively correlated with home hours except for 1975. The correlations imply that in cross sections rich people work more in the market, but less at home, and enjoy less leisure. This also implies that rich people are rich not only because they are better paid but also because they work longer hours.

Table 2 reports the averages of time use for each survey year. Leisure has increased over time for each of the four measures. Both market hours and home hours have decreased. The last row of Table 2 show the ratio of average home hours to average market hours. Between 1965-2003, the ratio declined from 0.709 to 0.643 . In their

full sample, Aguiar and Hurst (2007a) also find that market hours 
Table 1: Correlation Between Wage Rate and Time Use

\begin{tabular}{|c|c|c|c|c|c|}
\hline year & 1965 & 1975 & 1985 & 1993 & 2003 \\
\hline & \multicolumn{5}{|c|}{ Weekly Wage Rate (in 1965 dollars) } \\
\hline \multirow[t]{2}{*}{ Leisure 1} & -0.512 & -0.543 & -0.136 & -0.401 & -0.26 \\
\hline & $(0.210)$ & $(0.192)$ & $(0.216)$ & $(0.099)$ & $(0.016)$ \\
\hline \multirow[t]{2}{*}{ Leisure 2} & -0.584 & -0.701 & -0.179 & -0.558 & -0.713 \\
\hline & $(0.179)$ & (0.199) & $(0.196)$ & (0.039) & $(0.017)$ \\
\hline \multirow[t]{2}{*}{ Leisure 3} & -0.646 & -0.725 & -0.444 & -0.707 & -0.559 \\
\hline & $(0.169)$ & $(0.204)$ & $(0.220)$ & $(0.037)$ & $(0.026)$ \\
\hline \multirow[t]{2}{*}{ Leisure 4} & -0.665 & -0.798 & -0.378 & -0.592 & -0.634 \\
\hline & $(0.192)$ & $(0.208)$ & $(0.230)$ & $(0.055)$ & $(0.037)$ \\
\hline \multirow[t]{2}{*}{ Home Hours } & -0.256 & 0.470 & -0.630 & -0.390 & -0.567 \\
\hline & $(0.200)$ & $(0.158)$ & $(0.164)$ & $(0.108)$ & $(0.185)$ \\
\hline \multirow[t]{2}{*}{ Market Hours } & 0.544 & 0.607 & 0.660 & 0.741 & 0.650 \\
\hline & $(0.177)$ & $(0.073)$ & $(0.203)$ & $(0.154)$ & $(0.043)$ \\
\hline
\end{tabular}

This table reports correlations between wage and leisure, wage and home hours, and wage and market hours in cross sections. In parenthesis are bootstrapped standard errors.

Table 2: Average Time Use in Cross Sections

\begin{tabular}{rrrrrr}
\hline \hline year & 1965 & 1975 & 1985 & 1993 & 2003 \\
\hline Leisure 1 & 31.17 & 30.66 & 33.02 & 35.57 & 33.41 \\
Leisure 2 & 103.13 & 103.68 & 106.00 & 107.94 & 105.83 \\
Leisure 3 & 107.20 & 106.91 & 110.29 & 111.13 & 112.18 \\
Leisure 4 & 110.73 & 111.34 & 113.39 & 114.35 & 116.23 \\
Home Hours & 23.75 & 20.14 & 21.55 & 18.46 & 20.26 \\
Market Hours & 33.52 & 36.52 & 33.06 & 35.19 & 31.52 \\
Home Hours & 0.709 & 0.552 & 0.652 & 0.525 & 0.643 \\
\hline \hline
\end{tabular}

This table reports the average hours per week of leisure, home hours and market work in the 5 waves of ATUS in our sample. The last row shows the decline of home hours relative to market hours. 
declined to larger extent than home hours. ${ }^{11}$ Later this fact will be used to identify the growth of home production TFP.

Figure 1 plots the average wage rate and time allocation against time, with the time allocation variables rescaled. Clearly, wage rate and leisure are positively correlated over time. Although both home hours and market hours have decreased between 1965-2003, the decreases are not monotonic. The negative co-movement between market hours and home hours is evident in the figure. In the estimation, this is used to identify the relative productivity of labor at home and in the market. ${ }^{12}$

Figure 1: Time Series of Wage and Time Use

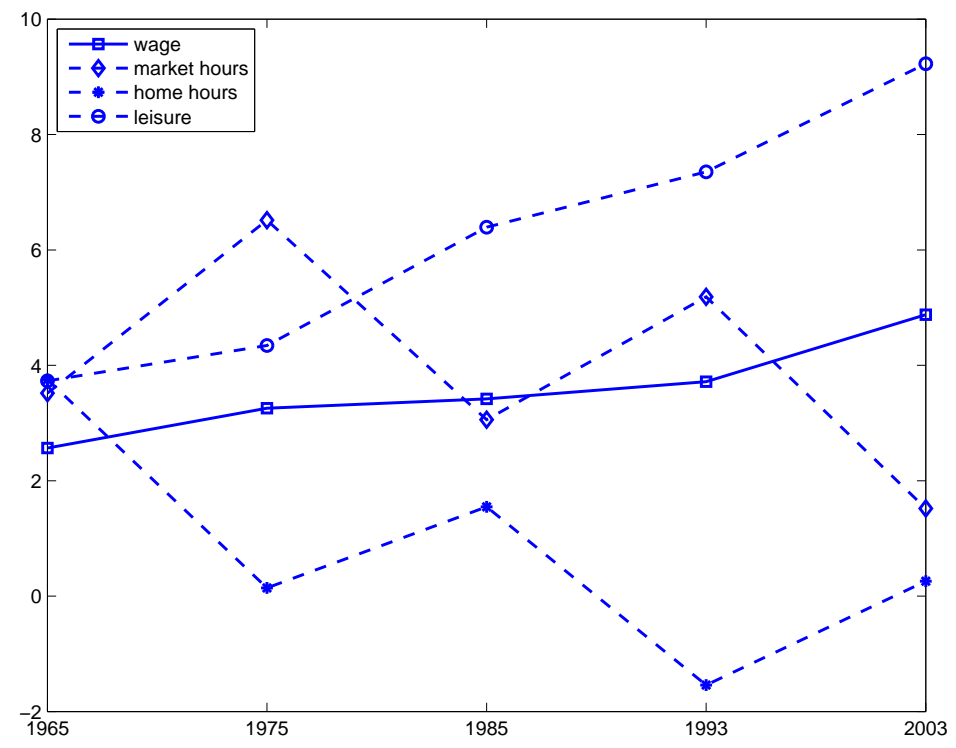

The figure shows the average wage rate, market hours, home hours and leisure over time. Leisure refers to leisure measure 4, so the sum of market hours, home hours and leisure is $7^{*} 24=168$. The time allocation variables are re-scaled.

\footnotetext{
${ }^{11}$ This is mainly driven by the large decrease of men's market hours.

${ }^{12}$ Similar negative co-movement is found in cross country data, with countries engaging in more market work spend less hours in home production. See Burda et al. (2008), Freeman and Schettkat (2001) and Ragan (2007).
} 
Figure 2 shows the scatter plots of home hours and leisure (measure 4) against market hours. Both home hours and leisure are strongly negatively correlated with market hour, with the correlation coefficients being -0.81 and -0.56 . Similar results are found using other measure of leisure. On the other hand, the correlation between home hours and leisure is very weak, not significantly different from zero. These facts are well explained in our model. We will return to this point after estimating the model.

Figure 2: Correlation Between Market Hours, Home Hours and Leisure
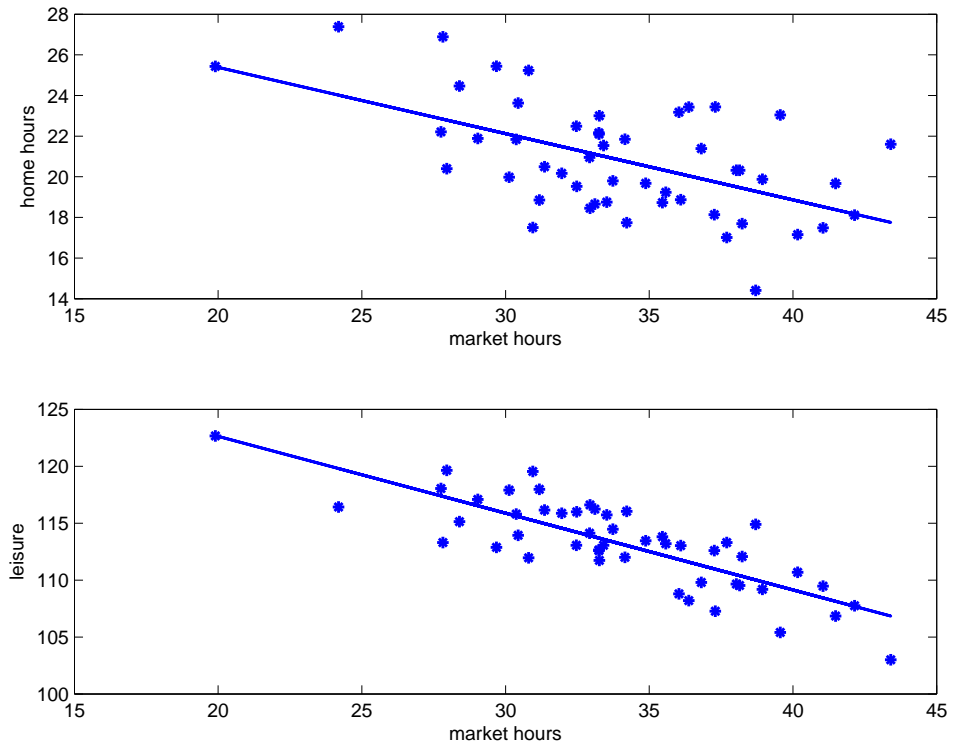

The figure are scatter plots from the pooled data. The upper panel shows the correlation between market hours and home hours. The lower panel shows the correlation between market hours and leisure. The fitted lines are obtained by running OLS. 


\section{The Model}

In this section we present a model of optimal time allocation which can generate the established facts in section 2. In the model, an agent takes the wage rate and home production technology as given, and maximizes utility by allocating time among market hours, home hours and leisure. We also discuss why a home production model that abstracts from home production TFP faces difficulty in explaining the documented time use patterns.

\subsection{Model Setup}

An agent derives utilities from the composition of consumption goods $c$ and leisure $\ell$ and solves the following optimization problem.

$$
\max _{h^{m}, h^{n}, \ell, c} u(\ell, c)
$$

s.t.

$$
\begin{aligned}
& x=w h^{m}+t r \\
& c=g\left(x, h^{n} \mid z, A\right) \\
& \ell=T-h^{m}-h^{n}
\end{aligned}
$$

where

$$
\begin{aligned}
& x=\text { market goods expenditure } \\
& h^{m}=\text { market hours } \\
& t r=\text { transfer } \\
& h^{n}=\text { home hours } \\
& \mathrm{T}=\text { total time endowment } \\
& z=\text { labor augmenting home production technology } \\
& A=\text { home production TFP } \\
& g\left(x, h^{n} \mid z, A\right)=\text { home production function }
\end{aligned}
$$

Here, we interpret transfer in equation (1) as the sum of government transfer, non-labor income and changes of assets. Transfer does not affect our estimation below, because we employ data on expenditure directly. 
The functional forms of utility and home production are

$$
\begin{aligned}
& u(\ell, c)=\left[\alpha \ell^{1-1 / \theta}+(1-\alpha) c^{1-1 / \theta}\right]^{\frac{1}{1-1 / \theta}} \\
& g\left(x, h^{n} \mid z, A\right)=A\left[(1-\rho) x^{1-1 / \sigma}+\rho\left(z h^{n}\right)^{1-1 / \sigma}\right]^{\frac{1}{1-1 / \sigma}},
\end{aligned}
$$

where $\theta$ is the elasticity of substitution between leisure and consumption, and $\sigma$ is the elasticity of substitution between home hours and market goods. It will be clear that the two elasticities are critical in time allocation.

Our modeling of home production follows Becker (1965). Home production combines market goods and home hours to produce consumption goods. ${ }^{13}$ Some existing studies treat market sector and home sector symmetrically, assuming both to take capital and labor as inputs and produce consumption goods. ${ }^{14}$ The way home production is modeled here can be viewed as a special case of this two-sector modeling, with home capital submerged into market expenditure.

The model is a static one that focuses on the intra-temporal optimal allocation. Beside its the simplicity, this treatment avoids the complication from inter-temporal elasticity of substitution which is known to be closely related to intra-temporal time allocation (Campbell and Ludvigson (2001)). In addition, an infinite horizon model entails the existence of balanced growth path. However in our model we allow leisure, home hours and market hours to have time series trends driven by home production TFP, thus we are not able to resort to balanced growth path to deal with nonstationarity arising from the growth of productivity or wage.

\footnotetext{
${ }^{13}$ Hamermesh (2008) assumes that "eating at home" is produced by combining eatingrelated time and goods, and accomplishes the direct estimates of home production of eating.

${ }^{14}$ Examples include Greenwood and Hercowitz (1991) Benhabib et al. (1991) and McGrattan et al. (1997).
} 


\subsection{First Order Conditions and Mechanisms}

First order conditions with respect to $h^{m}$ and $h^{n}$ yield two equations:

$$
\begin{gathered}
w \frac{\partial g}{\partial x} \times \frac{\partial u}{\partial c}=\frac{\partial u}{\partial \ell} \\
\frac{\partial g}{\partial h^{n}} \times \frac{\partial u}{\partial c}=\frac{\partial u}{\partial \ell}
\end{gathered}
$$

Combining (6) and (7) yields

$$
w \frac{\partial g}{\partial x}=\frac{\partial g}{\partial h^{n}}
$$

Both sides of equation (8) represent price of leisure in terms of the numeraire - consumption goods $c$. Therefore $w^{*}=w \frac{\partial g}{\partial x}=\frac{\partial g}{\partial h^{n}}$ is the effective wage rate. If an agent gives up one unit of leisure, she can put that time into home production. The marginal product of the home hours is $\frac{\partial g}{\partial h^{n}}$. Alternatively, she can choose to work more in the market, earning $w$, which in turn is put into home production. So the marginal product of market time is $w \frac{\partial g}{\partial x}$. In equilibrium, the marginal product of market time must equal to that of home hours.

Simply manipulating the first-order conditions gives the following two equations:

$$
\begin{aligned}
\log \left(h^{n}\right)=- & \sigma \log \left(\frac{1-\rho}{\rho}\right)+\log \left(\frac{x}{w}\right)+(\sigma-1) \log \left(\frac{z}{w}\right) \\
\log (\ell)= & \text { constant }+(1-\theta) \log (A)+\log (x)-\theta \log (w) \\
& +\frac{\sigma-\theta}{\sigma-1} \log \left[1+\left(\frac{\rho}{1-\rho}\right)^{\sigma}\left(\frac{z}{w}\right)^{\sigma-1}\right]
\end{aligned}
$$

where constant $=\theta \log \left(\frac{\alpha}{1-\alpha}\right)+\sigma \frac{1-\theta}{\sigma-1} \log (1-\rho)$

From equation (9), the impact of LAT $(z)$ on home hours depends on value of $\sigma$. If market goods and home hours are substitutes $(\sigma>1)$, home hours increases with the LAT, and vice versa. Notice that home production TFP does not directly impact home hours. Equation (10) shows that the impacts of $\operatorname{TFP}(A)$ on leisure depend on $\theta$, the substitutability between consumption and leisure. If $\theta<1$, then higher 
A will induce agents to take more leisure to complement the increased consumption.

For expositional purposes, we set the transfer in equation (1) to zero, so that $x=w h^{m}$. Plugging this into equation (9) and (10) leads to

$$
\log \left(\frac{h^{n}}{h^{m}}\right)=-\sigma \log \frac{1-\rho}{\rho}+(\sigma-1) \log \frac{z}{w}
$$

and

$$
\begin{aligned}
\log \left(\frac{\ell}{h^{m}}\right) & =\text { constant }+(1-\theta) \log (A)+(1-\theta) \log (w) \\
+ & \frac{\sigma-\theta}{\sigma-1} \log \left[1+\left(\frac{\rho}{1-\rho}\right)^{\sigma}\left(\frac{z}{w}\right)^{\sigma-1}\right]
\end{aligned}
$$

Equation (11) shows that economic agents shift time between market work and home production in response to changes in the relative productivity $\frac{z}{w}$. This enables us to explain the co-movement of home hours and market hours plotted in Figure 1. Equation (12) shows that the allocation of time between market work and leisure depends on both home production TFP and relative productivity $\frac{z}{w}$. In summary, changes of home production technology are directly related to the shifts of time between market work and home production, and between market work and leisure. This is consistent with the negative correlations between $h^{m}$ and $h^{n}$, and between $h^{m}$ and $\ell$, as shown in Figure 2.

\subsection{Why Home Production TFP}

Why is it difficult for a model without home production TFP to explain the time use patterns in both time series and cross sections? From (10), absent TFP, the time series increase of leisure can be driven either by increases of wage rate or by changes of $\frac{z}{w}$, the relative productivity. In the former case, correlation between wage rate and leisure in cross sections would also be positive, which is inconsistent with the data. Now the problem becomes whether the rising leisure can be driven by changes of $\frac{z}{w}$. 
Claim 1: If $\frac{z}{w}$ does not decrease with w, i.e., the advantage of higher-wage households in home production does not outweighs that in the market, then the time series rise of leisure between 1965-2003 is NOT driven by changes in $\frac{z}{w}$.

See the proof in Appendix B. The intuition is simple. If $\frac{z}{w}$ has decreased over time, equation (10) (also equation (12)) predicts that agents should have shifted time from leisure to market work. Thus leisure should decrease over time, rather than increase. On the other hand, if $\frac{z}{w}$ has increased, then agents should have shifted time from market work to home production, which is inconsistent with the fact that the ratio of market hours to home hours has decreased, as shown in the last row of Table 2 .

\section{Estimation}

In this section, we estimate the growth factors of home production technology and model parameters, and show the estimated model explains the documented time use patterns quite well. We then further illustrate the impacts of home production technology on time allocation.

\subsection{Estimation Strategy}

We use the Minimum Distance Estimator to estimate the growth factors of LAT and TFP along with model parameters. Home production technology can hardly be measured directly from the data. Hence, we normalize both LAT and TFP in 1965 to 1, The set of parameters to be estimated is $\Theta=\{\rho, \sigma, \alpha, \theta\}$. We summarize the symbols of parameters and technology as follows. 


\begin{tabular}{cl}
\hline Symbol & \multicolumn{1}{c}{ Definition } \\
\hline$\rho$ & share of home hours in home production function \\
$\sigma$ & ES between market goods and home hours \\
$\alpha$ & share of leisure in utility function \\
$\theta$ & ES between consumption and leisure \\
$L A T$ & labor-augmenting home production technology \\
$F T P$ & total factor productivity in home production \\
\hline
\end{tabular}

We assume that agents of different income deciles adopt the same home production technology at any point in time. Over time, LAT grows at varying rates. Therefore we estimate the growth factors of LAT for four intervals: 1965-1975, 1975-1985, 1985-1993, 1993-2003. However we restrict the growth rate of TFP to be a constant. The reason of the restriction will be clear in the next section as we examine how technology shapes time allocation. Simply speaking, TFP causes no cross sectional variations in time use, hence it is impossible to identify varying growth rates. Totally there are 9 unknowns to pin down.

We choose the parameter values and home production technology so that the model can match a set of data moments. The moments needs to be sensitive to parameters and able to summarize the features of our model and data. The first two moments are from the two first order conditions. That is

$$
\begin{aligned}
& 0=w \frac{\partial g}{\partial x} \times \frac{\partial u}{\partial c}-\frac{\partial u}{\partial \ell} \\
& 0=\frac{\partial g}{\partial h^{n}} \times \frac{\partial u}{\partial c}-\frac{\partial u}{\partial \ell}
\end{aligned}
$$

These conditions govern the optimal intra-temporal allocation of time and goods, hence are closely related to the share parameters as well as the substitutability parameters.

The second set of moments are the averages of market hours and home hours in the five waves of survey data. These averages are informative about technology growth rates. Specifically, the shifts of production time between home and market, as shown in Figure 1, help us pin down the growth rates of home production technology. 
Finally, the first order conditions should be orthogonal to the level of time use, therefore our third set of moments comes from the product of average market hours and home hours with the first order conditions in equation (13) and (14). This ensures that the first order conditions hold no matter how time allocation is shifted by changes of wage rate and home production technology. In total, we have 32 moments to target. With 9 unknowns, the number of overidentifying restrictions is 23 .

\subsection{Estimation Results}

The estimation results are reported in table 3. Consumption and leisure are estimated to be complements in the utility function. The estimated elasticity of substitution is below one, while the log-log preference commonly used in the literature assumes unit elasticity. The estimated elasticity of substitution between home time and market goods is around 2.1. In the literature it ranges from 1.6 to 2.5. For example, it is between 1.6 and 2 in Rupert, Rogerson and Wright (1995), depending on the demographic group. The estimate is 2 in Aguiar and Hurst (2007a), 1.8 in McGrattan, Rogerson and Wright (1997), and 2.3 in Chang and Schorfheide (2003).

Growth factor of LAT was high during 1965-1975 and 1993-2003, but low in other periods. This pattern is consistent through different measures of leisure. During 1965-2003, LAT increased by a factor of about 1.8. The corresponding annual growth rate is about $1.56 \%$ It should be noted that changes of tax code is not modeled explicitly, but they affect real wage rate. Therefore in the estimation they are captured by LAT growth.

Based on leisure 2, leisure 3 and leisure 4, TFP has grown at a factor of about 1.07-1.14 every decade, which amounts to annual growth rate of between $0.068-0.132 \%$. Using leisure 1 , TFP growth rate is about $3.5 \%$ per annum. The J-statistics show that the model is not reject at $10 \%$ using leisure 1.

Using the estimated parameter values and technology, we simulate 
Table 3: Estimation Results

\begin{tabular}{|c|c|c|c|c|c|c|c|c|c|}
\hline & $\begin{array}{l}1965- \\
1975\end{array}$ & $\begin{array}{l}1975- \\
1985\end{array}$ & $\begin{array}{l}1985- \\
1993\end{array}$ & $\begin{array}{l}1993- \\
2003\end{array}$ & $\sigma$ & $\rho$ & $\theta$ & $\alpha$ & J-stat \\
\hline \multicolumn{10}{|c|}{ Leisure 1} \\
\hline \multirow[t]{2}{*}{ LAT } & 1.146 & 1.042 & 1.000 & 1.433 & 2.108 & 0.549 & 0.892 & 0.307 & 3.311 \\
\hline & $(0.15)$ & $(0.14)$ & $(0.15)$ & $(0.27)$ & $(0.23)$ & $(0.02)$ & $(0.23)$ & $(0.03)$ & $(\mathrm{p}=0.93)$ \\
\hline \multirow[t]{2}{*}{ TFP } & \multicolumn{9}{|c|}{1.410} \\
\hline & \multicolumn{9}{|c|}{$(1.46)$} \\
\hline \multicolumn{10}{|c|}{ Leisure 2} \\
\hline \multirow[t]{2}{*}{ LAT } & 1.221 & 1.002 & 1.000 & 1.505 & 2.101 & 0.545 & 0.890 & 0.633 & 5.814 \\
\hline & $(0.15)$ & $(0.13)$ & $(0.14)$ & $(0.28)$ & $(0.16)$ & $(0.02)$ & $(0.22)$ & $(0.04)$ & $(p=0.74)$ \\
\hline \multirow[t]{2}{*}{ TFP } & \multicolumn{9}{|c|}{1.141} \\
\hline & \multicolumn{9}{|c|}{$(0.658)$} \\
\hline \multicolumn{10}{|c|}{ Leisure 3} \\
\hline \multirow[t]{2}{*}{ LAT } & 1.207 & 1.011 & 1.000 & 1.527 & 2.174 & 0.552 & 0.863 & 0.648 & 8.138 \\
\hline & $(0.16)$ & $(0.12)$ & $(0.13)$ & $(0.27)$ & $(0.14)$ & $(0.02)$ & $(0.23)$ & $(0.05)$ & $(\mathrm{p}=0.54)$ \\
\hline \multirow[t]{2}{*}{ TFP } & \multicolumn{9}{|c|}{1.088} \\
\hline & \multicolumn{9}{|c|}{$(0.44)$} \\
\hline \multicolumn{10}{|c|}{ Leisure 4} \\
\hline \multirow[t]{2}{*}{ LAT } & 1.222 & 1.000 & 1.000 & 1.542 & 2.184 & 0.552 & 0.860 & 0.658 & 8.558 \\
\hline & $(0.16)$ & $(0.12)$ & $(0.14)$ & $(0.27)$ & $(0.14)$ & $(0.02)$ & $(0.24)$ & $(0.05)$ & $(p=0.50)$ \\
\hline \multirow[t]{2}{*}{ TFP } & \multicolumn{9}{|c|}{1.070} \\
\hline & \multicolumn{9}{|c|}{$(0.40)$} \\
\hline
\end{tabular}

The table reports results of minimum distance estimation based on different measures of leisure. The factors of growth of LAT and TFP are per decade. In parenthesis are standard errors. 
market hours, home hours and leisure from the model. In simulation, we take wage and market expenditure from the real data exogenously, and calculate optimal time allocation based on equation (9) and (10). Figure 3 shows the average time use for different survey years, both from real data and simulated data. The simulated data closely track the trend of time allocation in the real data. Specifically, the simulated data can generate similar magnitude of increase in leisure and decrease in home hours and market hours as in the data.

Figure 3: Time Use Trends, Model vs Data
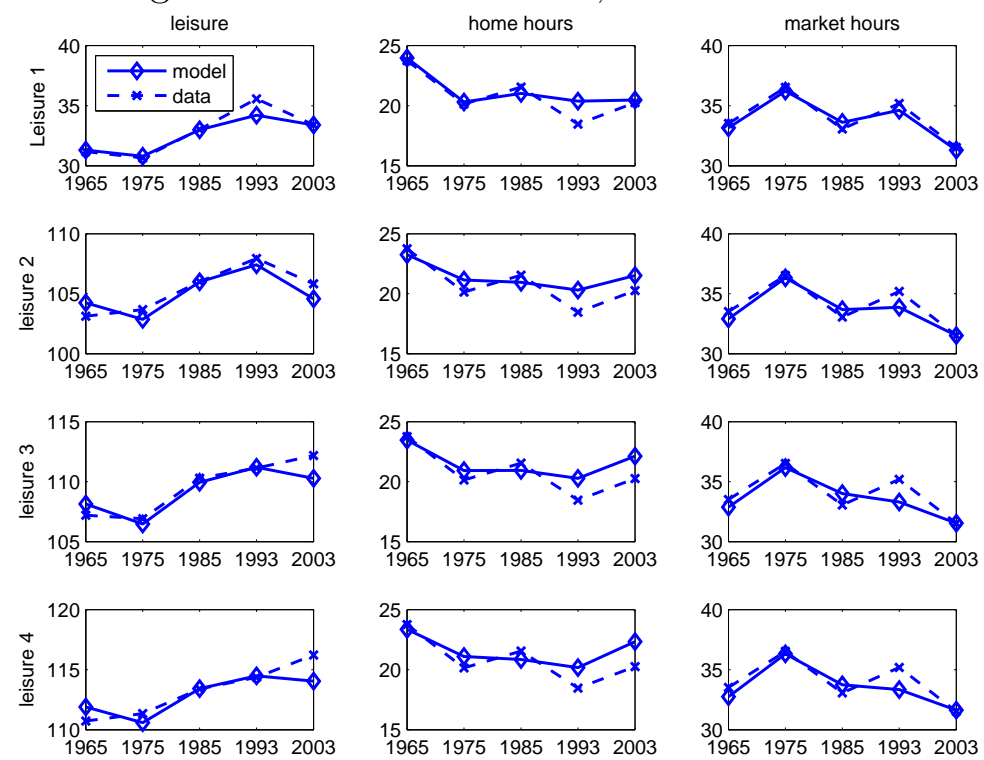

The figure compares the weekly averages of market hours, home hours and leisure from the model to those in the data. Averages from the model depend on the leisure measure used in the estimation. Results from using leisure 1 is reported in the top panel. Results from using leisure 2 is reported in the second-to-top panel, and so on.

Table 4 reports the cross sectional correlation between time use and wage rate in the simulated data for each survey year. For comparison, we also report the correlations in the real data. Except for the correlation between home hours and wage rate in 1975, all the 
correlations generated from the model have the same signs as in the data. As for 1975, the correlation in the data is positive between home hours and wage rate, which is inconsistent with other years, hence the estimated model based on all the available data fails to reproduce it.

Table 4: Correlation Between Wage and Time Use: Model vs Data

\begin{tabular}{|c|c|c|c|c|c|c|}
\hline year & & 1965 & 1975 & 1985 & 1993 & 2003 \\
\hline \multicolumn{7}{|c|}{ Weekly Wage Rate (in 1965 dollars) } \\
\hline \multirow[t]{2}{*}{ Leisure 1} & Data & -0.512 & -0.543 & -0.136 & -0.401 & -0.26 \\
\hline & Model & -0.525 & -0.303 & -0.285 & -0.566 & -0.821 \\
\hline \multirow[t]{2}{*}{ Leisure 2} & Data & -0.584 & -0.701 & -0.179 & -0.558 & -0.713 \\
\hline & Model & -0.508 & -0.32 & -0.278 & -0.563 & -0.832 \\
\hline \multirow[t]{2}{*}{ Leisure 3} & Data & -0.646 & -0.725 & -0.444 & -0.707 & -0.559 \\
\hline & Model & -0.510 & -0.312 & -0.281 & -0.555 & -0.843 \\
\hline \multirow[t]{2}{*}{ Leisure 4} & Data & -0.665 & -0.798 & -0.378 & -0.592 & -0.634 \\
\hline & Model & -0.508 & -0.316 & -0.278 & -0.552 & -0.846 \\
\hline \multirow[t]{2}{*}{ Home Hours } & Data & -0.256 & 0.470 & -0.630 & -0.390 & -0.567 \\
\hline & Model & -0.866 & -0.788 & -0.944 & -0.936 & -0.948 \\
\hline \multirow[t]{2}{*}{ Market Hours } & Data & 0.544 & 0.607 & 0.660 & 0.741 & 0.650 \\
\hline & Model & 0.836 & 0.745 & 0.866 & 0.880 & 0.952 \\
\hline
\end{tabular}

The table compares the cross sectional correlations between wage and time use from the model to those in the data.

\subsection{Technology and Time Allocation}

In our model both TFP and $\frac{z}{w}$ are major driving forces in optimal time allocation, which is evident from equation (9) and (10). In this section we further investigate how the two forces affect time allocation in both cross sections and time series. 


\subsubsection{Relative Labor Productivity $\left(\frac{z}{w}\right)$ and Time Allo- cation}

Figure 4 plots market hours, home hours and leisure from the real data against $\frac{z}{w}$, where $\mathrm{z}$ is estimated and $\mathrm{w}$ is from the real data. Evidently, as $\frac{z}{w}$ declines, time spent on home production becomes less productive. Since home hours and market goods are substitutes, households will optimally allocate more time to market work and less time to home work.

Figure 4: Relative Productivity and Time Allocation
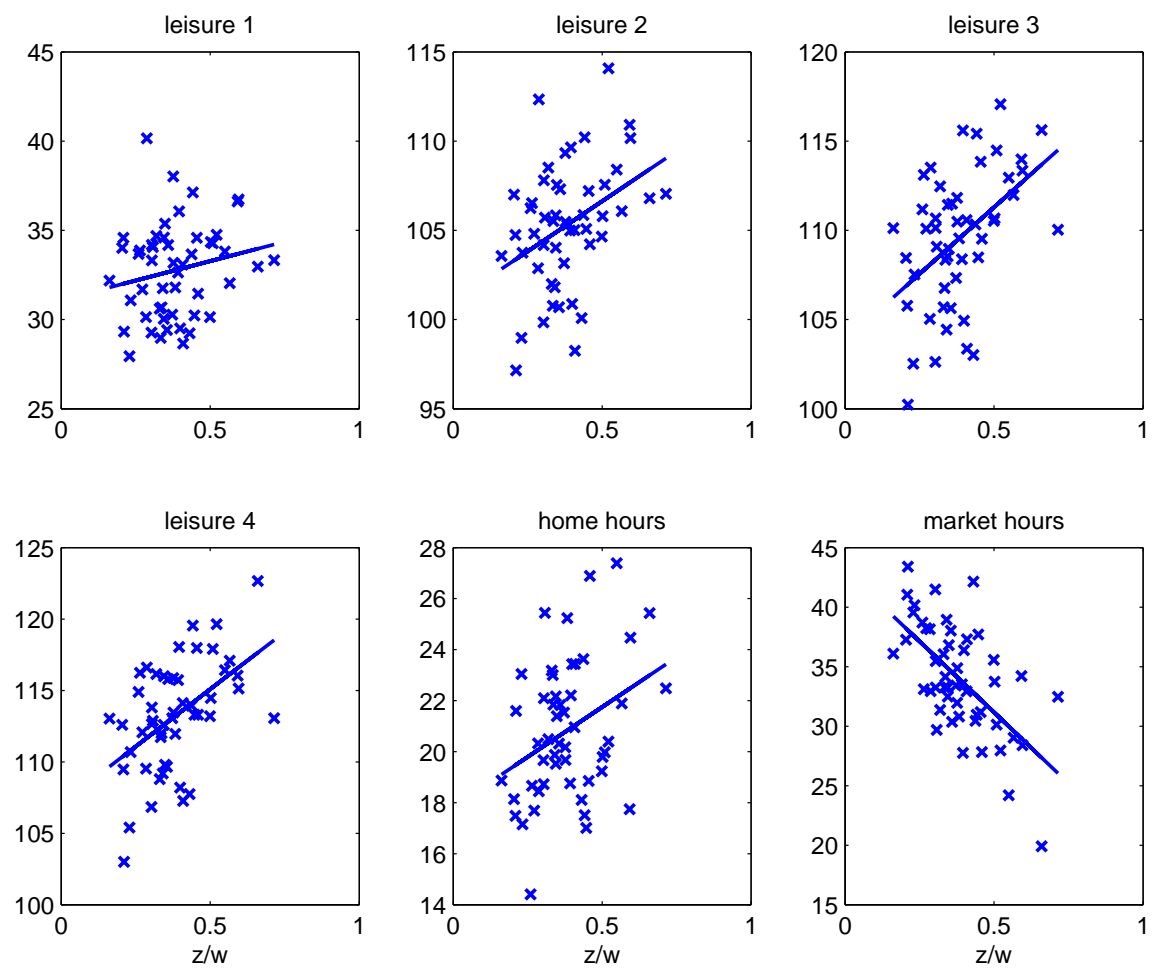

The figure plots time allocation against $\frac{z}{w}$. The fitted lines are obtained by running OLS.

It follows that in the cross sections rich agents will work more in the market and less at home since they have lower $\frac{z}{w}$. In the model 
without home production, $\theta<1$ implies that income effects dominant substitution effects and rich households should enjoy more leisure. However, when home production is explicitly modeled, an increase in wage (decrease in $\frac{z}{w}$ ) has one additional effect on leisure - the reduction in home hours results in the reduction in the composite consumption, which in turn leads to the reduction in leisure due to the complementarity. The relative magnitude of the two effects is determined by the relative size of the two elasticities. Figure 4 shows that the second effect dominates in our estimated model. The intuition for the cross sectional time allocation can also be applied to the time series. According to our estimation, $\frac{z}{w}$ has declined slightly over time. Therefore, if home production TFP had not changed over time, we should have observed an increase in market hours and a decrease in home hours and leisure over time. However, due to the rise of home production TFP, in reality market hours had decreased and leisure had increased.

\subsubsection{Home Production TFP and Time Allocation}

Figure 5 plots time use from real data against home production TFP denoted by the corresponding years. Since we assume agents in the same cross section adopt the same home production technology, there is no cross sectional variation of TFP. When TFP improves, agents can produce the composite consumption good more efficiently. The complementarity between consumption and leisure then implies the increase in leisure.

\section{Implications on Income Tax and La- bor Supply}

We use the estimated model to examine the response of time allocation to income taxation and lump-sum transfer. We show how the effect of each of the two policies depends on home production technology and 
Figure 5: Home Production TFP and Time Allocation
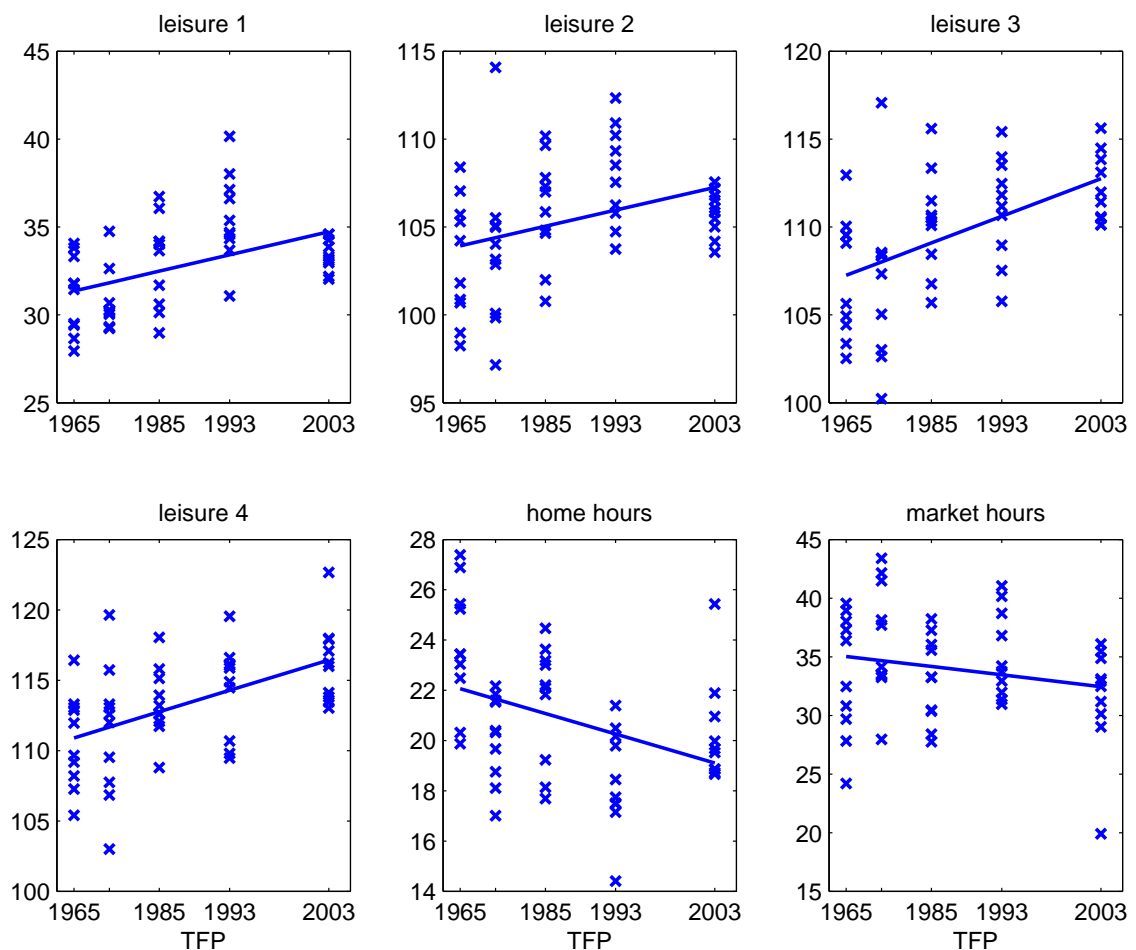

The figure plots time allocation against estimated TFP. TFP is labeled by the corresponding years. The fitted lines are obtained by running OLS. 
wage rate. Then we study the combined effect, assuming the government levies proportional tax and distributes the tax revenue evenly to households as lump-sum transfers. We qualitatively show how the policy effect differs to a model that abstracts from wage heterogeneity.

\subsection{Dependence of Policy Effect on Home Pro- duction Technology and Wage Rate}

For proportional income tax, we have the following claim. Claim 2: Assuming zero transfer, we have the following

1. Proportional income tax increases home hours and leisure, but reduces market hours.

2. The tax effect on time allocation is stronger when the levels of home production technology (both LAT and TFP) are higher.

3. The tax effect on time allocation is weaker for higher-wage agents.

See Appendix C for the proof.

To quantitatively assess the effect of proportional tax and lumpsum transfer, we take exogenously the decile level wage rates in the data and the estimated home production technology in 2003, and simulate optimal time allocation based on the estimated model parameters. Parameter estimates based on leisure 1 are used. The dashed line in Figure 6 shows the changes of time use due to a proportional tax of $5 \%$ and a lump-sum transfer that equals $5 \%$ of average income in 2003. Both policies decrease market labor supply, but the proportional tax shifts market hours mainly to home production while the lump-sum transfer shifts market hours mainly to leisure. Consistent with the prediction in claim 1 , tax effect is stronger among lower wage households. ${ }^{15}$

To illustrate to what extent the policy effect depends on home production technology, we conduct two experiments with results also shown in Figure 6. In the first experiment, we use LAT from 1993 in

\footnotetext{
${ }^{15}$ Households in lower income deciles have lower wage rates in the data.
} 
Figure 6: Changes of Time Use Due to Tax/Transfer
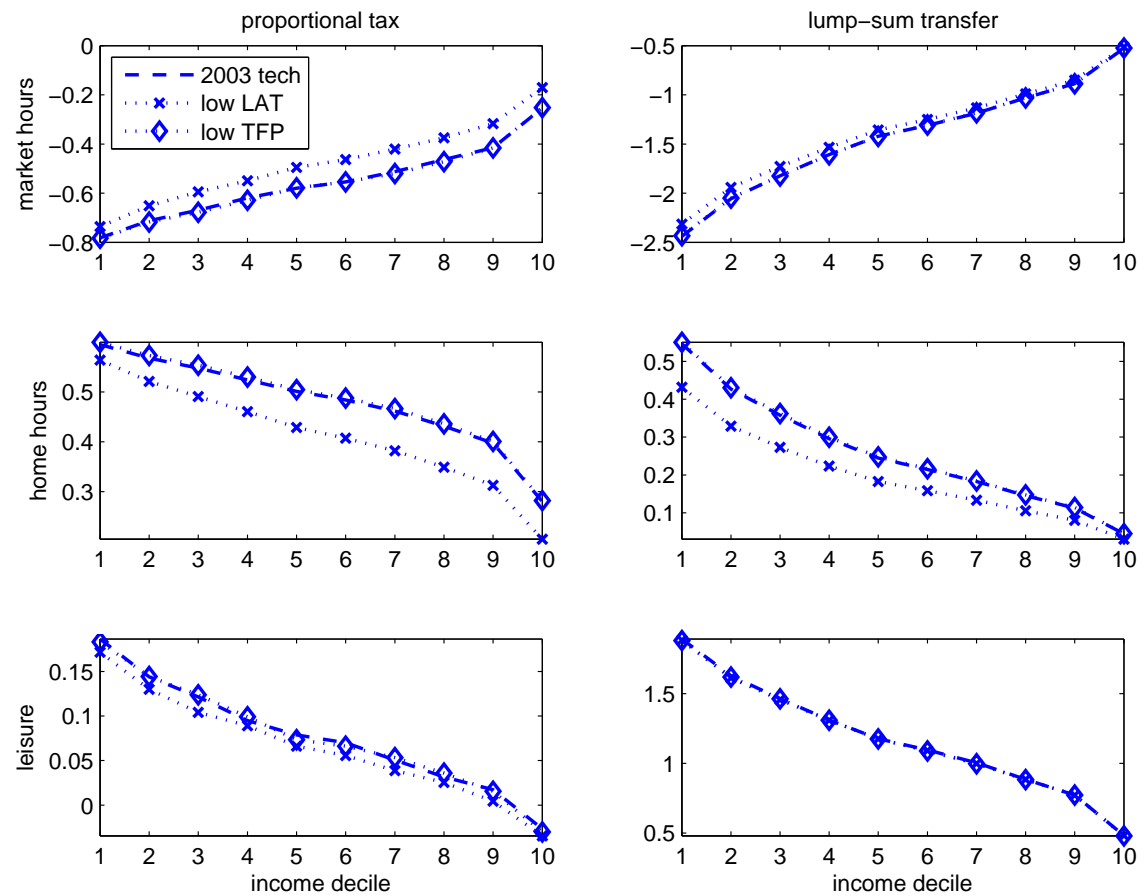

The figure plots the per-week changes of time use due to proportional income tax and lump-sum transfer. Proportional tax rate is $5 \%$, and lump-sum transfer equals $5 \%$ of average income in 2003. Home production is set to the level in 2003, except that labor-augmenting technology is take from 1993 in the "low LAT" case and home production TFP is taken from 1993 in the "low FTP" case. 
the simulation and keep everything else unchanged. Comparing the results from this "low LAT" case to those from high LAT (2003 technology), we find that effect of proportional tax on time use is clearly stronger when LAT is higher. Regarding the lump-sum transfer, the effects on market hours and home hours are also stronger when LAT is higher, but the effect on leisure is almost independent of LAT.

In the second experiment, we use home production TFP from 1993 and keep everything else unchanged. We find that quantitatively the effect of either policy on time allocation is almost independent of TFP.

The dependence of policy effect on wage rate and home production technology can have important macroeconomic implications. For example, during recessions wage rate is likely to be lower relative to home production technology, which implies that policy effect is counter-cyclical. We do not pursue quantitative assessments in this dimension within our static framework. Rather we proceed to assess the policy effect in cross sections.

\subsection{Comparison of Policy Effects}

Table 5: Wage Heterogeneity and Policy Effect

\begin{tabular}{ccccccccccc}
\hline \hline & \multicolumn{2}{c}{1965} & \multicolumn{2}{c}{1975} & \multicolumn{2}{c}{1985} & \multicolumn{2}{c}{1993} & \multicolumn{2}{c}{2003} \\
\hline & \multicolumn{2}{c}{$\begin{array}{c}\text { Heterog. } \\
\text { Wage }\end{array}$} & \multicolumn{2}{c}{ Heterog. } & \multicolumn{2}{c}{ Heterog. } & \multicolumn{2}{c}{ Heterog. } & \multicolumn{2}{c}{ Heterog. } \\
& \multicolumn{2}{c}{ Wage } & \multicolumn{2}{c}{ Wage } & \multicolumn{2}{c}{ Wage } & \multicolumn{2}{c}{ Wage } \\
\multicolumn{1}{c}{ yes } & no & yes & no & yes & no & yes & no & yes & no \\
\hline$h^{m}$ & -3.22 & -2.99 & -2.49 & -2.40 & -2.44 & -2.27 & -2.33 & -2.08 & -1.96 & -1.69 \\
$h^{n}$ & 1.01 & 0.94 & 0.82 & 0.79 & 0.80 & 0.75 & 0.76 & 0.68 & 0.72 & 0.64 \\
$\ell$ & 2.21 & 2.06 & 1.67 & 1.60 & 1.64 & 1.52 & 1.57 & 1.40 & 1.24 & 1.05 \\
\hline \hline
\end{tabular}

The table reports the changes of per-week time use due to tax and transfer. Tax rate is $5 \%$. In the heterogenous wage model, wage rates are the averages with each income decile. In the representative agent model, wage rates are the cross sectional averages in CPS data.

Since policy effect is stronger among low-wage households, wage heterogeneity is important. With positively skewed wage distribution, 
policy effect should be understated in a representative agent model. We study quantitatively how large the understatement can be. Tax rate is again $5 \%$, and the lump-sum transfer equals tax revenue. Computationally, we use a guess-and-verify strategy to find the level of transfer that is consistent with the tax rate and new optimal market labor supply after the policy is implemented.

We simulate policy effect based on wage rate and home production technology from different years. Wage rate in our model is heterogeneous, represented by the 10 income groups in each wave of survey. For the representative agent, we use the average wage in each wave. It is well-known that wage distribution in the US is positively skewed, therefore the mean wage rate is higher than the median. Since a representative agent model uses the mean wage implicitly or explicitly, its prediction of policy effect should be understated. Table 5 shows that, on average, the representative agent model understates the reduction of labor supply by about $8 \%$. The increase of both leisure and home hours is also understated by about $8 \%$. Notice that our model uses average wage at income decile level which itself understates the skewness of wage distribution. Therefore results from the representative agent model should be further away from those from a full-blown heterogeneous agents model.

\section{Conclusion}

Motivated by a rich set of time use patterns in both time series and cross sections, we have studied a model of time allocation in which home production technology plays key roles. We have considered two types of home production technology - labor-augmenting technology and total factor productivity. Each type has leading examples in real world and plays distinct roles in optimal time allocation. By linking data from ATUS, CEX and CPS, we have estimated the growth rates of home production technology as well as the key parameters in home production function and utility function. 
Using the model to study the effect of tax and transfer, we have found that the policy effect increases with the level of home production technology, but decreases with wage rate. One of the implications is that policy effect depends on wage distribution which is positively skewed in the US data. Based on the estimated model, a representative agent model understates the reduction of labor supply by about $8 \%$.

The finding that policy effect depends on home production technology also has interesting implications on the cyclical fluctuations of an economy with fiscal policy. We shall explore this dimension in the future research.

This paper has focused on intra-temporal optimal allocation of time. It is interesting to extend our model to capture the dynamics of time use and inter-temporal allocation within a lifecycle framework. We again leave this interesting extension to the future work.

\section{Appendix A: Data Appendix}

\section{Information about ATUS, CEX and CPS}

We use five waves of time use surveys: 1965-1966 American's Use of Time survey conducted by the Survey Research Center at the University of Michigan, 1975-1976 Time Use in Economic and Social Accounts survey conducted by the Survey Research Center at the University of Michigan, 1985 American's Use of Time survey conducted by the Survey Research Center at the University of Maryland, 1992-1994 National Human Activity Pattern Survey conducted by the Survey Research Center at the University of Maryland, and 2003 American Time Use Survey conducted by the Bureau of Labor Statistics. In this paper, these surveys are referred to as ATUS65, ATUS75, ATUS85, ATUS93, and ATUS2003.

Compared to other sources of information on time use, such as CPS and PSID, time use surveys have the advantage of providing 
detailed records of respondents activity for a full day. This enables us to empirically identify the trichotomy of work in the market, work at home and leisure as formalized by Gronau (1977). The time taxonomy proposed by Aguiar and Hurst (2007a) consistently organizes data from different waves of survey into the three categories. Given the disputes on whether certain activities should be classified as leisure, Aguiar and Hurst (2007a) define four measures of leisure, from the narrowest to the broadest. This paper follows their classification of market hours, home hours (termed non-market time in Aguiar and Hurst (2007a)) and leisure strictly.

Household level total expenditure data are extracted from Consumer expenditure Survey. Expenditure on consumer durables is included, because we do not model them as home production capital explicitly. Before 1980s only three waves of survey are conducted, in 1960-1961 (CEX61), 1972 (CEX72) and 1973 (CEX73) respectively. We interpolate income decile level expenditure for year 1965 and year 1975 from CEX61, CEX73 and CEX85. In interpolation we allow the growth rates of expenditure to differ across income deciles But for a given group we assume constant growth rate between the adjacent surveys.

We use March CPS from 1966, 1976, 1986, 1994, 2004 to estimate income decile level wage rates. The March supplement records the earnings of household members from the previous year. defined as the sum of wages and salaries with overtime pay, commissions, or tips included. March CPS also records the weeks worked, usual weekly hours, age and educational attainment for each member in the surveyed households. The individual wage rate is calculated by dividing total work hours in a year from total earnings. Then for the $i^{t h}$ income group in year $t$, average wage rate is calculated as $w_{i, t}=0.5 w_{i, t}^{m}+0.5 w_{i, t}^{f}$, where $w_{i, t}^{m}$ is the mean after-tax wage rate for husband, and $0.5 w_{i, t}^{f}$ is the mean after-tax wage for working wives.

Prior to 1976, usual weekly hours for the previous year are not available, we use hours worked during the survey week instead. Fol- 
lowing Katz and Murphy (1992), top coded earnings are multiplied by 1.45. Given that our analysis is based on the averages of income deciles, these treatments should have little effect on the results.

\section{Major Activities Included in Various Measures of Leisure}

We list the major activities included in each leisure measure. The list is for the convenience of readers and is not exhaustive. The classification is taken from Aguiar and Hurst (2007a).

- Leisure 1: entertainment, relaxing, social activities and active recreation. e.g. watching $\mathrm{TV}$, going to theater, sports and games.

- Leisure 2: Leisure 1 plus eating, sleeping and personal care.

- Leisure 3: Leisure 2 plus childcare, including basic childcare, playing with the child and teaching the child.

- Leisure 4: Leisure 3 plus education, civic and religious activities, caring for other adults and own medical care.

\section{Appendix B: Proof of Claim 1}

Using equation (11) and (12), taking derivative of $\log \left(\frac{h^{n}}{h^{m}}\right)$ and $\log \left(\frac{\ell}{h^{m}}\right)$ with respect to $\frac{z}{w}$ yields

$$
\begin{aligned}
& \frac{\partial \log \left(\frac{h^{n}}{h^{m}}\right)}{\partial\left(\frac{z}{w}\right)}=(\sigma-1) \frac{w}{z} \\
& \frac{\partial \log \left(\frac{\ell}{h^{m}}\right)}{\partial\left(\frac{z}{w}\right)}=(\sigma-\theta) \frac{\left(\frac{\rho}{1-\rho}\right)^{\sigma}\left(\frac{z}{w}\right)^{\sigma-2}}{1+\left(\frac{\rho}{1-\rho}\right)^{\sigma}\left(\frac{z}{w}\right)^{\sigma-1}}
\end{aligned}
$$

Totally there are 3 cases to discuss.

1. $\sigma>1$ and $\sigma>\theta$. In this case, $\frac{\partial \log \left(\frac{\ell}{h^{m}}\right)}{\partial\left(\frac{z}{w}\right)}>0$ and $\frac{\partial \log \left(\frac{h^{n}}{h^{m}}\right)}{\partial\left(\frac{z}{w}\right)}>0$. Thus for leisure to increase relative to market hours, $\frac{z}{w}$ needs 
to increase, which in turn means home hours relative to market hours should increase. But the ratio of home production time to market work has decreased between 1965-2003. A contradiction!

2. $\sigma>1$ and $\sigma<\theta$. In this case, equation (12) predicts that higher wage should induce more leisure and less market work, which contradicts with the cross sectional correlations

3. $\sigma<1$. In this case, $\frac{\partial \log \left(\frac{h^{n}}{h^{m}}\right)}{\partial\left(\frac{z}{w}\right)}<0$. Thus in cross sections rich households would work less in the market and more at home, unless their advantage in home production outweighs that in the market, i.e, $\frac{w}{z}$ decrease with $\mathrm{w}$, which is precluded. Q.E.D.

\section{Appendix C: Proof of Claim 2}

From equation (11) and (12) we have the following derivatives of time use with respect to wage rate.

$$
\begin{aligned}
& \frac{d\left(h^{n} / h^{m}\right)}{d w}=-\frac{h^{n}}{h^{m}} \frac{\sigma-1}{w}<0 \\
& \frac{d\left(\ell / h^{m}\right)}{d w}=-\frac{\ell}{h^{m}} \frac{1}{w}\left[\frac{\sigma-\theta}{1+\left(\frac{\rho}{1-\rho}\right)^{\sigma}\left(\frac{z}{w}\right)^{\sigma-1}}+1-\sigma\right]<0
\end{aligned}
$$

With the estimated parameter values, the above inequality must hold, which is consistent with the cross sectional correlation between wage and time use. This proves the first point in Claim 2, because the effect of levying (or increasing) proportional income tax is exactly the same as reducing real wage rate.

What we need to show is that such tax effect increases with LAT and TFP, but diminishes with wage rate w. Mathematically, it suffices to show that

$$
\begin{aligned}
& \text { 1. } \quad \frac{d^{2}\left(h^{n} / h^{m}\right)}{d w^{2}}>0, \quad \frac{d^{2}\left(\ell / h^{m}\right)}{d w^{2}}>0 \\
& \text { 2. } \quad \frac{d^{2}\left(h^{n} / h^{m}\right)}{d w d z}<0, \quad \frac{d^{2}\left(\ell / h^{m}\right)}{d w d z}<0, \quad \frac{d^{2}\left(\ell / h^{m}\right)}{d w d A}<0
\end{aligned}
$$

That is, the second derives with respect to $w$ have the opposite signs as the first derivatives in (17) and (18), and the cross derivatives with respect to $z$ and $A$ have the same sigh as the first derivatives. 
Using (11) and (17), we derive

$$
\begin{aligned}
& \frac{d^{2}\left(h^{n} / h^{m}\right)}{d w^{2}}=\exp \left[-\sigma \log \left(\frac{1-\rho}{\rho}\right)+(\sigma-1) \log \left(\frac{z}{w}\right)\right] \frac{\sigma-1}{w^{2}}>0 \\
& \frac{d^{2}\left(h^{n} / h^{m}\right)}{d w d z}=-\exp \left[-\sigma \log \left(\frac{1-\rho}{\rho}\right)+(\sigma-1) \log \left(\frac{z}{w}\right)\right] \frac{(\sigma-1)^{2}}{w z}<0
\end{aligned}
$$

where the first inequality holds because $\sigma>1$.

Now we turn to the second (cross) derivatives of $\ell / h^{m}$. The first derivative in (18) involves the product of three terms $-\frac{\ell}{h^{m}}, \frac{1}{w}$ and the bracketed term. Each term is a function of wage rate and home production technology. Applying the product rule, we have

$$
\begin{aligned}
\frac{d^{2}\left(\ell / h^{m}\right)}{d w^{2}}= & -\frac{d\left(\ell / h^{m}\right)}{d w} \frac{1}{w}\left[\frac{(\sigma-\theta)}{1+\left(\frac{\rho}{1-\rho}\right)^{\sigma}\left(\frac{z}{w}\right)^{\sigma-1}}+1-\sigma\right] \\
& +\frac{\ell}{h^{m}} \frac{1}{w^{2}}\left[\frac{(\sigma-\theta)}{1+\left(\frac{\rho}{1-\rho}\right)^{\sigma}\left(\frac{z}{w}\right)^{\sigma-1}}+1-\sigma\right] \\
& +\frac{\ell}{h^{m}} \frac{1}{w}(\sigma-\theta)(\sigma-1) \frac{\left(\frac{\rho}{1-\rho}\right)^{\sigma} z^{\sigma-1} w^{-\sigma}}{\left[1+\left(\frac{\rho}{1-\rho}\right)^{\sigma}\left(\frac{z}{w}\right)^{\sigma-1}\right]^{2}}
\end{aligned}
$$

Each of the three additive terms are positive, so $\frac{d^{2}\left(\ell / h^{m}\right)}{d w^{2}}>0$. Notice that the first term is positive because $\frac{d\left(\ell / h^{m}\right)}{d w}<0$. Also the bracketed term must be positive given our parameter values.

Applying product rule, the cross derivatives are given by

$$
\begin{aligned}
\frac{d^{2}\left(\ell / h^{m}\right)}{d w d z}= & -\frac{d\left(\ell / h^{m}\right)}{d z} \frac{1}{w}\left[\frac{(\sigma-\theta)}{1+\left(\frac{\rho}{1-\rho}\right)^{\sigma}\left(\frac{z}{w}\right)^{\sigma-1}}+1-\sigma\right] \\
& -\frac{\ell}{h^{m}} \frac{1}{w}(\sigma-\theta)(\sigma-1) \frac{\left(\frac{\rho}{1-\rho}\right)^{\sigma}\left(\frac{z}{w}\right)^{\sigma-1} \frac{1}{z}}{\left[1+\left(\frac{\rho}{1-\rho}\right)^{\sigma}\left(\frac{z}{w}\right)^{\sigma-1}\right]^{2}}<0
\end{aligned}
$$

where the inequality holds because $\frac{d\left(\ell / h^{m}\right)}{d z}>0$ which is easy to see from (12).

$$
\frac{d^{2}\left(\ell / h^{m}\right)}{d w d A}=-\frac{d\left(\ell / h^{m}\right)}{d A} \frac{1}{w}\left[\frac{(\sigma-\theta)}{1+\left(\frac{\rho}{1-\rho}\right)^{\sigma}\left(\frac{z}{w}\right)^{\sigma-1}}+1-\sigma\right]<0
$$


where the inequality holds because $\frac{d\left(\ell / h^{m}\right)}{d A}>0$. Q.E.D.

\section{References}

Aguiar, Mark and Eric Hurst, "Measuring trends in leisure: the allocation of time over five decades," Quarterly Journal of Economics, 2007, 122 (3), 969-1006.

- and Erik Hurst, "Life-Cycle Prices and Production," American Economic Review, December 2007, 97 (5), 1533-1559.

Becker, Gary S., "A Theory of the Allocation of Time," The Economic Journal, 09 1965, 75 (229), 493-517.

Benhabib, Jess, Richard Rogerson, and Randall Wright, "Homework in macroeconomics: household production and aggregate fluctuations," ournal of Political Economy, 1991, 99 (6), 11661187.

Burda, Michael C., Daniel S. Hamermesh, and Philippe Weil, The Distribution of Total Work in the EU and US, Oxford University Press, 2008.

Campbell, John Y and Sydney Ludvigson, "Elasticities of Substitution in Real Business Cycle Models with Home Protection," Journal of Money, Credit and Banking, November 2001, 33 (4), $847-75$.

Chang, Yongsung and Frank Schorfheide, "Labor-supply shifts and economic fluctuations," Journal of Monetary Economics, November 2003, 50 (8), 1751-1768.

Costa, Dora L., "The wage and the length of the work day: from the 1890s to 1991," Journal of Labor Economics, 2000, 18 (1), 156-181. 
Freeman, Richard B and Ronald Schettkat, "Marketization of Production and the US-Europe Employment Gap," Oxford Bulletin of Economics and Statistics, Special I 2001, 63 (0), 647-70.

Greenwood, Jeremy and Guillaume Vandenbroucke, "Hours worked: long-run trends," Economie d'avant garde Research Report, $2005,(10)$.

- and Zvi Hercowitz, "The allocation of capital and time over the business cycle," Journal of Political Economy, 1991, 99 (6), 11881214 .

Gronau, Reuben, "Leisure, home production and work - the theory of the allocation of time revisited," Journal of Public Economics, 1977, 85 (6), 1099-1123.

Hamermesh, Daniel, "Direct Estimates of Household Production.," Economics Letters, 2008, 98 (1), 31-34.

Hamermesh, Daniel. and Jungmin Lee, "Stressed out on four continents: time crunch or yuppie kvetch?," The Review of Economics and Statistics, 2007, 89 (2), 374-383.

Juhn, Chinhui and Kevin M. Murhpy, "Wage inequality and family labor supply," Journal of Labor Economics, 1997, 15 (1), $72-97$.

Katz, Lawrence F. and Kevin M. Murphy, "Changes in relative wages, 1963-1987: supply and demand factors," Quarterly Journal of Economics, 1992, 107 (1), 35-78.

Kuhn, Peter. and Fernando Lozano, "The expanding workweek? understanding trends in long work hours among U.S. men, 19792004," Journal of Labor Economics, 2008, 26 (2), 311-343.

McDaniel, Cara E., "Forces Shaping Hours Worked in the OECD 1960-2004," American Economic Journal: Macroeconomics, 10 2011, 3 (4), 27-52. 
McGrattan, Ellen.R., Richard Rogerson, and Randall Wright, "An equilibrium model of the business cycle with household production and fiscal Policy," International Economic Review, 1997, 38 (2), 267-290.

Mincer, Jacob, "Labor force participation of married women," Aspects of Labor Economics: Princeton University Press, 1962, pp. 267-290.

Ragan, Kelly, "Taxes, Transfers and Time Use: Fiscal Policy in a Model of Household Production," 2007 Meeting Papers 681, Society for Economic Dynamics 2007.

Rogerson, Richard, "Structural Transformation and the Deterioration of European Labor Market Outcomes," Journal of Political Economy, 04 2008, 116 (2), 235-259.

_ , "Market Work, Home Work, and Taxes: A Cross-Country Analysis," Review of International Economics, 08 2009, 17 (3), 588-601.

Rupert, Peter, Richard Rogerson, and Randall Wright, "Estimating Substitution Elasticities in Household Production Models," Economic Theory, June 1995, 6 (1), 179-93.

_, _, and _, "Homework in labor economics: household production and intertemporal substitution," Journal of Monetary Economics, 2000, 46 (3), 557-579. 